\title{
The New Era of Energy Transition: Challenges, Investment Opportunities and Technological Innovations
}

\author{
Guest Editors: Kostas Andriosopoulos and Spiros Papaefthimiou
}

https://doi.org/10.5547/01956574.40.SI1.kand

It is an undeniable fact that we are witnessing a new evolving era in the global energy scenery. This non-stable situation poses serious questions, challenges and opportunities for countries, industries, professionals and academics. The objective of this special issue is to focus on the energy sector which should constantly adapt to global and local uncertain environments due to continuously changing geopolitical and social conditions, and to present new research results in the areas of decision-making mechanisms in the energy markets and energy pricing, smart networks design and management, environmental and energy efficiency analysis. In summary, the papers in this issue touch upon a range of central topics in the fields of energy and related markets, pointing at major existing and future energy and environmental challenges. All these stimulating views provide both policymakers and market participants with the utmost important research output for policy development and monitoring purposes.

Topics concerning European energy related issues, are the focus of some of the papers in the special issue. For example, E. Galariotis, I. Kalaitzoglou, K. Kosmidou, S. Papaefthimiou and S.I. Spyrou in "Could Market Making be Profitable in The European Carbon Market?" investigate when market making can be profitable in the European Carbon Futures market, by developing an order type selection rule, based solely on transaction level data. Results indicate that market orders are always less profitable than limit orders. In addition, market makers are expected to derive most of their profits in a low trading intensity environment, mainly due to higher liquidity commissions and a lower probability of dealing with better informed agents. In contrast, an unconditional limit order submission strategy from an off-floor trader should not be preferred, apart from a medium trading intensity environment, where information and liquidity premia adequately compensate them for execution and information risk.

In "Environmental and Energy Efficiency of EU Electricity Industry: An Almost Spatial Two Stages DEA Approach", S. Bigerna, M.C. D’Errico and P. Polinori analyze the relationship between the energy efficiency and the stringency of environmental and market regulations in the electricity sectors for 19 EU countries between 2006 and 2014. Their results suggest that market and environmental regulations have not unidirectional impacts on the three components of total factor productivity.

M. Balcilar, D. Roubaud and M. Shahbaz in their paper "The Impact of Energy Market Uncertainty Shocks on Energy Transition in Europe", study the effects of energy market uncertainty shocks on energy transition in the 28 European Union countries from 1990 to 2015, using annual frequency data. They assess the effects of oil price as well as the energy market supply, demand, and residual price shocks, using a time-varying parameter panel data stochastic volatility model. The results indicate the importance of reducing energy market uncertainty to the success of a clean energy transition in Europe, as uncertainties have strong time-varying effects on the transition from fossil fuels to renewable energy. 
The paper "Evaluation of Risks for Electricity Generation Companies through Reconfiguration of Bidding Zones in Extended Central Western Europe" by C. Deilen, T. Felling, R. Leisen and C. Weber focuses in Central Western Europe where a reconfiguration of bidding zones for electricity is frequently discussed as a way to improve congestion management. The current EU guideline on Capacity Allocation and Congestion Management even envisages reviews of the bidding zone configuration (BZC) in regular intervals of three years. Such a change of BZCs gives rise to additional regulatory risk for generation companies. Their expected net present value depends on local prices, which are directly influenced by the BZC. The paper develops a methodology to investigate the impact of this regulatory risk which is modeled using a partly-meshed scenario tree. The risk factors reflected therein are uncertainties in grid developments, in combination with other risks such as changing coal and gas spreads, demand, or renewable infeed variations. Results are compared to the current BZC in Europe and to a nodal setup.

In their contribution "Strategic Behaviour in a Capacity Market? The New Irish Electricity Market Design", J. Teirilä and R.A. Ritz describe how the transition to a low-carbon power system requires growing the share of generation from renewables while ensuring security of supply and thus policymakers and economists increasingly see a capacity mechanism as a way to deal with this challenge. Yet this raises new concerns about the exercise of market power by large players via the capacity auction. They present a new modelling approach that captures such strategic behaviour together with a set of ex ante empirical estimates for the new Irish electricity market design.

"Heterogeneous Returns to Scale of Wind Farms in Northern Europe" by G. Benini, M. Carvalho, L. Gaudard, P. Jochem and K. Madani, tries to identify the optimal size of a wind farm using North European data. An empirical analysis of 61 sites constructed between 2004 and 2014 suggests that economies-of-scale are highly heterogeneous across on-shore and off-shore projects. The resulting scale elasticities suggest that small on-shore farms have a bigger per-turbines output than off-shore ones, while the opposite is true for big projects.

"A Multicriteria Assessment Approach to the Energy Trilemma" by A. Pliousis, K. Andriosopoulos, M. Doumpos and E. Galariotis deals with the energy trilemma concept which emphasizes the need to achieve a balance among three main dimensions: energy security, energy equity, and environmental sustainability. The study provides a systematic treatment of the energy trilemma at a country level employing a novel multicriteria assessment framework, to evaluate the related performance of countries. Such an evaluation provides useful results for policy making, as it enables the examination of the status of each country and the challenges that it faces in achieving energy sustainability.

Two papers focus on United States: T.H. Van Hoang, S.J.H. Shahzad, R.L. Czudaj and J.A. Bhat in "How Do Oil Shocks Impact Energy Consumption? A Disaggregated Analysis for the U.S." investigate the interaction between energy consumption and oil shocks in the U.S. from 1974 to 2018. Energy consumption is disaggregated in distinguishing between renewable and non-renewable energy consumption results show that renewable energy consumption responds the most to aggregate demand and oil supply shocks while for non-renewable energy consumption, it is oil demand shocks. The dynamic connectedness results show that oil supply and demand shocks spillover the most to hydropower consumption while aggregate demand shocks spillover the less. However, these relationships change over time and recommend the flexibility of energy policies.

In "Common Unobserved Determinants of Intraday Electricity Prices", N.S. Thomaidis, G.H. Dash and N. Kajiji employ multilevel factor modelling techniques to unravel systematic unobserved determinants of the intraday and interzonal price curve dynamics for the US Pennsylvania-New Jersey-Maryland (PJM) interconnection. The authors argue that a multilevel factor ap- 
proach offers a more systematic and transparent representation of intertemporal and cross-sectional patterns in PJM electricity prices compared to alternative brute-force VARMAX parametrizations and the single-level factor models, which are often put forward in the literature as viable modelling alternatives.

Apart from EU and USA, papers representing countries from the the rest of the world are also included in the special issue. K. Matsumoto, Y. Shigetomi, H. Shiraki, Y. Ochi, Y. Ogawa and T. Ehara in "Addressing Key Drivers of Regional $\mathrm{CO}_{2}$ Emissions of the Manufacturing Industry in Japan" investigated the factors behind the historical changes in $\mathrm{CO}_{2}$ emissions of the Japanese manufacturing industry as a whole and by sector at a prefectural level from 1990 to 2013. The results indicate that energy intensity, structure, and activity effects were more influential in the changes of emissions than the carbon intensity effect. Among the eight considered industrial sectors of Japan's manufacturing industry, the changes in the chemistry and metal sectors were particularly complex and thus improvements in these two sectors should be prioritized.

S. Moon, D.-J. Lee, T. Kim and K.-T. Kim in "An Estimation of Market-Based Carbon-Emission Prices Using Comparative Analogy: A Korean Case" estimate the market-based prices of carbon credits in Korea by using a comparative analogy approach with those of EU ETS. They compare the estimated and the actual observed prices and analyze the reasons for the existing gap between both prices.

In "Directed Technical Change, Capital Intensity Increase and Energy Transition: Evidence from China", D. Wang, A. Mugera and B. White analyze the causes of China's energy transition since 1978 and show that increasing capital intensity causes transition to modern energy sources (such as solar electricity) in the long run, but not vice versa. They conclude that China's energy transition is driven by capital deepening and biased technical change towards capital-intensive modern energy in the long run.

“China vs. The Rest: A New Era of Global Energy Dealmaking” by Q. Wang and G. Kretzschmar, studies 726 global oil and gas mergers and acquisitions for the period 2006 to 2012 and suggest that by undertaking deals in risky countries, typically those with high trade barriers to entry and significant political risk, China achieves observably more favourable deal pricing terms, achieving acquisitions at significant discount.

Fossil fuels have been the cornerstone for the global energy sector and the paper "Living in an era where market fundamentals determine crude oil price" by T. Perifanis and A. Dagoumas, aims at quantifying the impact of the fundamental drivers of crude oil price over the period 20082017 using monthly data. Results unveil the importance of both factors of demand and supply to affect the price and present evidence on the considerable impact of S\&P crude oil index, as a "paper oil" market indicator.

E. Kyritsis and A. Serletis in "Oil Prices and the Renewable Energy Sector" investigate the effects of oil price shocks, and also of uncertainty about oil prices, on the stock returns of clean energy and technology companies. Their results indicate that oil price uncertainty has no statistically significant effect on stock returns, and that the relationship between oil prices and stock returns is symmetric.

A similar question is investigated by A. Gianfreda, L. Parisio and M. Pelagatti in "The RES-Induced Switching Effect Across Fossil Fuels: An Analysis of Day-Ahead and Balancing Prices". Authors discuss upon the massive introduction of RES (fostered by generous supporting schemes) in electricity generation, that has influenced the shape and position of the supply function and consequently the equilibrium prices. Their results for Italy indicate that fuel prices are much less relevant in determining the dynamics of electricity prices in recent years characterized by high 
RES penetration, while on the contrary, taking into account flexible thermal sources and fuel prices (especially gas) are in a long run equilibrium.

The special issue concludes with two interesting contributions. G.H.M. Bjertnæs in "Efficient Combinations of Taxes on Fuel and Vehicles" shows that a tax on fuel should be combined with heavier taxation of fuel-efficient vehicles to curb externalities from road traffic. The tax on fuel is implemented in order to curb externalities linked to both consumption of fuel and road use. A heavier tax on fuel-efficient vehicles prevent motorists from avoiding the road user charge on fuel by purchasing fuel-efficient vehicles.

"Storage Business Models: Lessons for Electricity from Cloud Data, Frozen Food and Natural Gas" by K.L. Anaya and M.G. Pollitt, evaluates different well-established non-electric storage markets (cloud data, frozen food and natural gas) in order to identify relevant lessons for electrical energy storage (EES) connected to electricity distribution networks. The evaluation of the three case studies (Google Drive-cloud storage, Oakland International-frozen food storage and Centrica Storage-gas storage) suggests that well-developed business models already exist in growing and mature storage markets. Regulation plays also an important role across the different storage markets and business model components, however its importance varies depending on the type of market. Innovation in storage business models is also observed (technological and contractual) which should also be facilitated in EES.

Summarizing, the papers in this special issue tried to enlighten various topics on the energy sector which has completely evolved in recent years, aiming at stressing the fact that the new era of energy transition will be full of challenges, investment opportunities and technological innovations. 